\title{
Magnesium carbonate and rosin powders stabilize sliding motion between rubber-gloved human hand and grasped cylindrical bar
}

\author{
Takeshi YAMAGUCHI* and Kazuo HOKKIRIGAWA* \\ ${ }^{*}$ Graduate School of Engineering, Tohoku University \\ 6-6-01, Aramaki-Aza-Aoba, Aoba-ku, Sendai, Miyagi 980-8579, Japan \\ E-mail: yamatake@gdl.mech.tohoku.ac.jp
}

Received 30 December 2014

\begin{abstract}
We investigated the effect of magnesium carbonate and rosin powders, conventionally used as anti-slip agents, for the ease of controlling the sliding motion of a stainless steel bar grasped vertically by a hand wearing a rubber glove. Fifteen participants were instructed to slide the stainless steel bar downward with their dominant hand and control the sliding speed to be constant by controlling their grip force, and stop the bar $0.2 \mathrm{~m}$ from the starting point within $5.0 \mathrm{~s}$. Sliding control tests were conducted under six conditions of the interface between gloved-hand and the bar: dry without powder, dry with $\mathrm{MgCO}_{3}$ powder, dry with rosin powder, wet without powder, wet with $\mathrm{MgCO}_{3}$ powder, and wet with rosin powder. The bar sliding motion was captured and the time of arrival, total sliding distance of the bar, and standard deviation of the sliding velocity of the bar were calculated. The friction force between sliding bar and gloved-hand was estimated from the bar sliding motion. The controllability of the sliding motion of the bar was evaluated by sensory assessment. The sliding control test indicated that both powders reduced the variation in sliding velocity of the grasped bar and improved the controllability of its sliding motion compared with unpowdered dry and wet conditions. Powder application also decreased variation in the friction force between the rubber-gloved hand and the grasped bar during sliding under dry and wet conditions. These results suggest that both powders stabilize friction, thereby improving the sliding control of a grasped bar.
\end{abstract}

Key words : Hand, Friction, Powder, Grasp, Control

\section{Introduction}

Sports equipment with optimized friction behavior is necessary for good athletic performance in various disciplines that require either high friction (e.g., running, rock climbing, weight lifting) or low friction (e.g., ice skating, bar exercise, skiing). Slips between the athlete's hand and sporting equipment/gear are of critical concern. To prevent slips and enhance athletic performance, various anti-slip agents are applied to the hand or glove and equipment surfaces. Magnesium carbonate powder $\left(\mathrm{MgCO}_{3}\right)$ or rosin powder (mainly constituting $\mathrm{MgCO}_{3}$ powder and pine resin) is used as a powdery anti-slip agent in sports such as climbing, baseball, softball, and track and field events. $\mathrm{MgCO}_{3}$ powder is considered to absorb sweat and improve grip on the holds while climbing ( $\mathrm{Li}$, et al., 2001, Bourne, et al., 2011, Amca, et al., 2012). $\mathrm{MgCO}_{3}$ powder is also used in gymnastics. In this sport, the athletes' hands are covered with tapes or grips, which must slide across the equipment such as a horizontal bar. Therefore, the powders are considered to not only prevent slippage, but also to enhance the ability to 'control' sliding between hands and equipment. However, the effect of these powders on the ease of controlling the sliding between human hands and objects remains unclear.

Previous studies on slippage between human hands and objects sought to understand how humans grasp and manipulate objects with stability and precision. These studies focused on preventing the slippage of grasped objects (Burstedt, et al., 1999, André, et al., 2009, de Freitas, et al., 2009, Damian, et al., 2012). When grasping a vertically oriented object (Johansson and Westling, 1984), a perpendicular force must be applied against the opposite side of the 
object (known as the grip force) to prevent slippage caused by the tangential force component. Literature (Flanagan and Wing, 1995, Cole and Rotella, 1999) indicates that healthy individuals adapt their grip force to counteract continuous changes in the tangential force within an adequate safety margin which is defined as the difference between the tangential coefficient and static coefficient of friction. This adaptation of grip force to secure an adequate safety margin is implemented by the central nervous system and is necessary for the precise grasping of objects with different weights and surface characteristics (Blackmore, et al., 1998). However, whether sliding motion can be more easily controlled by varying the frictional characteristics between human hands and grasped objects is yet to be investigated.

The sliding friction between hands and a grasped object could be influenced by contact pressure and sliding velocity. More specifically, the friction of viscoelastic materials, such as unlubricated human skin, finger pads, and rubber gloves, decreases as contact pressure increases (Peter and Nackenhorst, 2007, Derler, et al., 2009, Kim, et al., 2013) and is strongly affected by sliding velocity (Ludema and Tabor, 1966, Bahadur and Ludema, 1971) under dry conditions. Under wet conditions, the friction of elastomer materials is affected by contact pressure, sliding velocity, and fluid viscosity because the lubrication mode is altered (Adams, et al., 2007). The central nervous system easily adapts some frictional characteristics to realize an effective grip force for sliding motion control. The above mentioned $\mathrm{MgCO}_{3}$ and rosin powders are expected to affect the frictional characteristics between hands/gloves and an object, and to influence sliding controllability.

The objective of this study was to investigate whether $\mathrm{MgCO}_{3}$ and rosin powder application can improve sliding motion control of cylindrical steel bar vertically grasped by a human hand wearing a rubber glove. The role of powder application on friction was also investigated under dry and wet conditions.

\section{Methods}

\subsection{Sliding motion control test of vertically grasped cylindrical object}

Fifteen young adults (thirteen men and two women) participated in this test. The mean of the participants' age was $23.4 \pm 1.5$ years (range: $21-28$ years). All subjects were right handed and none of them reported any previous hand pathologies. All subjects gave their informed consent to participate in the experiment.

The test investigated the effect of the powders on sliding motion control of a vertically grasped object. Participants were requested to vertically grasp a hollow, cylindrical stainless steel bar with their dominant hand while keeping their forearm on a desk (Fig. 1(a)). The participants were instructed to slide the bar downward with their hand on a start command, then control the sliding speed to be constant (to the best of their ability) by controlling their grip force, and stop the bar $0.2 \mathrm{~m}$ from the starting point within $5.0 \mathrm{~s} \mathrm{(Fig.} \mathrm{1(b)).}$

The participants wore a thin natural rubber glove (thickness: $0.13 \mathrm{~mm}$ ) to minimize the influence of skin surface lipids and sweat on their sliding control ability. The length and diameter of the bar were $662 \mathrm{~mm}$ and $19.05 \mathrm{~mm}$, respectively. The total mass of the bar and a weight was $500 \mathrm{~g}$. The test conditions of the interface between the bar and the participant's hand wearing the rubber glove were varied as follows: dry without powder, dry with $\mathrm{MgCO}_{3}$ powder (for athletic use; NT1951, NISHI athletic goods Co., Ltd), dry with rosin powder (Mizuno, 2ZA-416), wet without powder, wet with $\mathrm{MgCO}_{3}$ powder, and wet with rosin powder. Thus, each participant undertook six trials. The $\mathrm{MgCO}_{3}$ powder used in this study was $100 \%$ basic magnesium carbonate $\left(\mathrm{xMgCO}_{3} \cdot \mathrm{yMg}(\mathrm{OH})_{2} \cdot \mathrm{zH}_{2} \mathrm{O} ; \mathrm{x}, \mathrm{y}\right.$, and $\mathrm{z}$ are integer). The main ingredients of the rosin powder were magnesium carbonate, pine resin, aromatic petroleum resin, precipitated silica and tourmaline. The fingers and the entire palm of the glove were contacted with $\mathrm{MgCO}_{3}$ or rosin powder and the excess powder was brushed off. In the wet tests, the bar was sprayed with purified water (approximately $10 \mathrm{ml}$ ). The order of the test conditions was randomized to eliminate the learning effect. A new rubber glove was used for each trial condition. Temperature and relative humidity of the testing environment were controlled at $21{ }^{\circ} \mathrm{C} \pm 2{ }^{\circ} \mathrm{C}$ and $50 \% \pm 5 \%$ $\mathrm{RH}$, respectively.

The movement of the bar during the sliding trial was recorded at $30 \mathrm{fps}$ by a video camera. The positions of the tracking markers attached to the bar (marker 1) and the participant's hand (marker 2) (Fig. 1(a)) were detected by a tracking software (View Point, IDT Japan, Inc.). The vertical sliding velocity of the bar $v_{\mathrm{i}}$ in the $i$ th frame was calculated as follows: 


$$
\begin{aligned}
& v_{i}=\frac{L_{i+1}-L_{i-1}}{2 \Delta t} \\
& L_{i}=\left(z_{1, i}-z_{2, i}\right)-\left(z_{1,0}-z_{2,0}\right)
\end{aligned}
$$

where $L_{\mathrm{i}}$ is the relative sliding distance of the cylindrical bar and $\Delta t$ is the sampling time $(1 / 30 \mathrm{~s})$. The vertical $(z)$ coordinates of the tracking markers 1 and 2 are denoted by $z_{1,0}$ and $z_{2,0}$ before sliding (in frame zero), and by $z_{1, \mathrm{i}}$ and $z_{2, \mathrm{i}}$ in the $i$ th frame. The behavior of the bar during a trial was evaluated from the following measured and calculated variables:

- Time of arrival $T_{\mathrm{a}}$ [s]: duration from the starting time $t_{0}$ when the sliding velocity of the bar first exceeds $0.005 \mathrm{~m} / \mathrm{s}$ to the time $t_{\mathrm{n}}$ when the participant terminates the trial.

- Total sliding distance of the bar $L_{\mathrm{t}}[\mathrm{m}]$ : difference between the sliding distance at the trial termination time $t_{\mathrm{n}}$ and the distance at the starting time $t_{0}$.

- Standard deviation of the sliding velocity of the bar $\sigma_{\mathrm{v}}[\mathrm{m} / \mathrm{s}]$ : standard deviation of the sliding velocity during a trial.

The controllability of sliding motion of the bar was evaluated by sensory assessment. Participants were asked to rate the ease with which they could control the sliding motion of the bar under each condition, on a scale from 1 to 5 . A higher score indicated that the sliding motion was easier to control. Participants' grip strength was measured with a grip dynamometer before and after the trials.

According to a simple mechanical model of the vertically grasped bar, the friction force $F_{\mathrm{i}}$ between gloved-hand and sliding the grasped object in the $i$ th frame was estimated using the following equation:

$F_{\mathrm{i}}=m\left(g-a_{\mathrm{i}}\right)$

$a_{i}=\frac{v_{i+1}-v_{i-1}}{2 \Delta t}$

where $m$ is the mass of the bar, $a_{\mathrm{i}}$ is the vertical acceleration of the bar in the $i$ th frame, and $g$ is the gravitational acceleration.

Statistical analysis was performed using SPSS (version 19.0, Chicago, IL, USA). One-way repeated-measures analysis of variance (ANOVA) was used to evaluate whether the mean time of arrival, total sliding distance, standard deviation of the sliding velocity of the bar and friction force during sliding, and evaluation score were affected by the six rubber-gloved hand/bar interface conditions. Specific significant differences between the interface conditions were determined by post hoc paired $t$-testing with Bonferroni correction. The significance level was set at $p=0.05$.

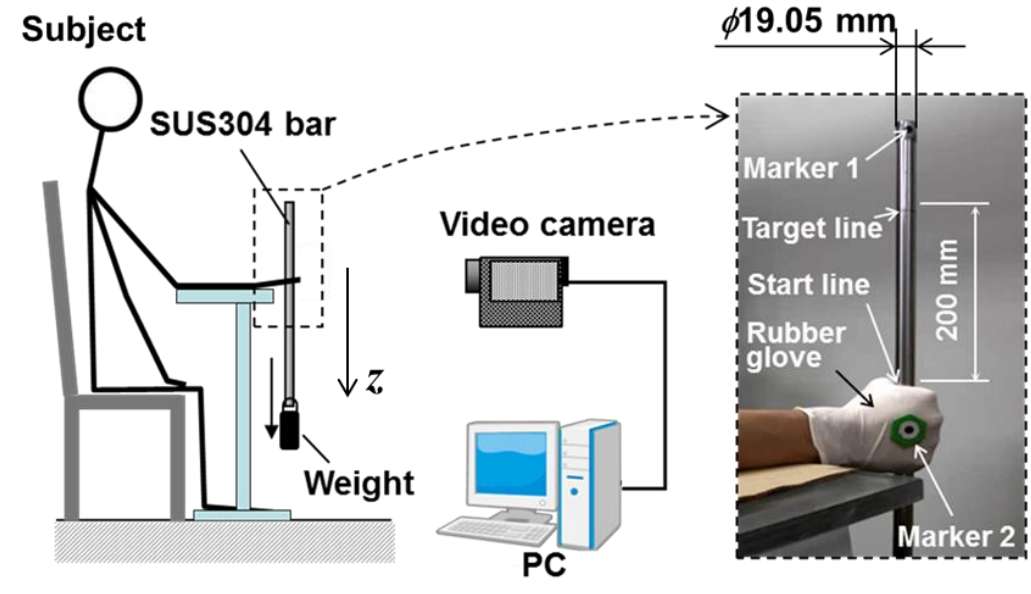

(a)

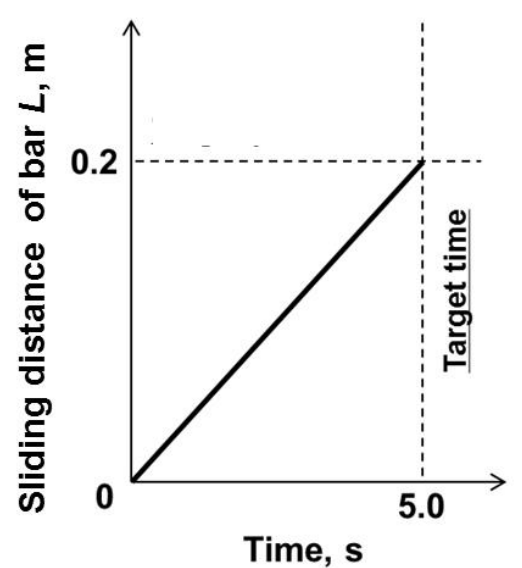

(b)

Fig. 1 (a) Experimental setup for the sliding control test; (b) instructed bar sliding motion 


\subsection{Ball-on-plate friction test}

Ball-on-plate friction tests were performed to investigate the role of $\mathrm{MgCO}_{3}$ and rosin powder application on the coefficient of friction between rubber and steel under dry and wet condition, as shown in Fig. 2. An austenitic stainless steel (JIS SUS304) ball with a diameter of $15.9 \mathrm{~mm}$ and a surface roughness $R a$ of $0.14 \mu \mathrm{m}$ was linearly slid against a $0.1 \mathrm{~mm}$-thick urethane rubber sheet mounted on a stainless steel plate. The sliding was conducted in unidirectional. The test conditions of the interface between the rubber sheet and steel ball were the same as those in the sliding control test: dry without powder, dry with $\mathrm{MgCO}_{3}$ powder, dry with rosin powder, wet without powder, wet with $\mathrm{MgCO}_{3}$ powder, and wet with rosin powder. Under powdery conditions, the rubber sheet was covered with $\mathrm{MgCO}_{3}$ or rosin powder and the excess powder was brushed off prior to each test. In the wet tests, purified water $(3 \mathrm{ml})$ was dropped onto the plate surface with a pipette and dispersed before the ball was placed on the plate. Normal load was 0.049, 0.098, 0.196, or $0.491 \mathrm{~N}$, and sliding velocity was $0.0001,0.001,0.01$, or $0.1 \mathrm{~m} / \mathrm{s} /$. The sliding distance was $0.05 \mathrm{~m}$. In the present study, the coefficient of friction was calculated from the mean frictional force during the period of constant sliding speed. The mean coefficient of friction was evaluated from five tests conducted under the identical sliding condition. Temperature and relative humidity of the testing environment were controlled at $21{ }^{\circ} \mathrm{C} \pm 2{ }^{\circ} \mathrm{C}$ and $50 \% \pm 5 \% \mathrm{RH}$.

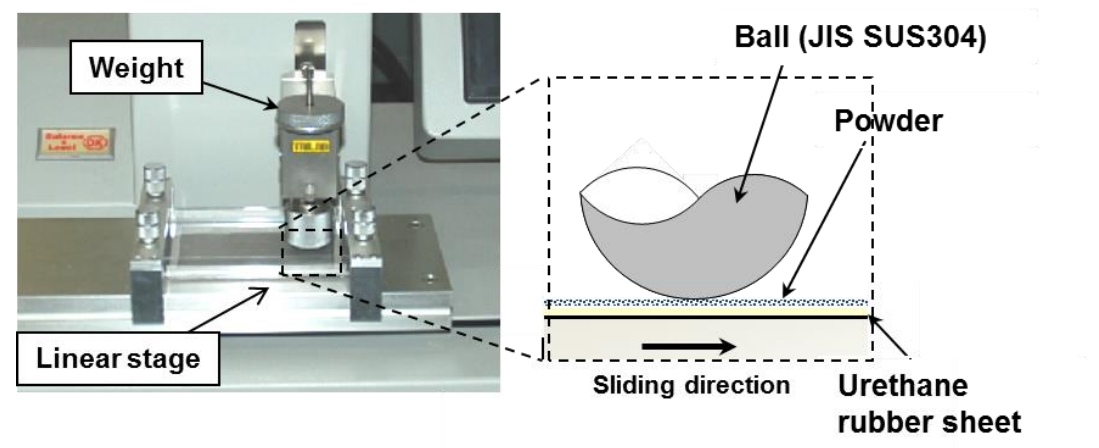

Fig. 2 Ball-on-plate friction apparatus

\section{Results}

\subsection{Effect of powders on control of sliding motion of grasped bar}

Mean grip strengths of the participants were $426 \mathrm{~N} \pm 96 \mathrm{~N}$ and $429 \mathrm{~N} \pm 103 \mathrm{~N}$ before and after the trials, respectively. Paired t-testing indicated that these values were not significantly different ( $\mathrm{p}>0.05)$, implying that grip strength was not reduced by fatigue during the repeated trials of grasping the bar.

Figure 3 shows representative temporal variations in the sliding distance of the bar. Results are shown for dry and wet conditions without $\mathrm{MgCO}_{3}$ powder and dry condition with $\mathrm{MgCO}_{3}$ powder. As shown in Fig. 3 (a) and (b), under both dry and wet conditions, the sliding movement was unstable without the powders. On the other hand, the sliding movement remained stable under the dry condition with $\mathrm{MgCO}_{3}$ powder, and the bar movement was terminated approximately $5.0 \mathrm{~s}$ after the start of sliding (Fig. 3 (c)). Figure 4 plots the temporal variation in the sliding velocity of the bar under dry and wet unpowdered conditions, and under $\mathrm{MgCO}_{3}$ powdered condition. In the unpowdered cases (Fig. 4 (a) and (b)), the sliding velocity of the bar significantly fluctuates and irregular spikes are observed. In contrast, the sliding velocity of the bar is stabilized by the powder application (Fig. 4(c)) compared with unpowdered conditions. Table 1 presents the mean and standard deviation of the evaluation score, time of arrival, total sliding distance, and standard deviation of sliding velocity of the bar for each gloved-hand/bar interface condition. One-way repeated-measures ANOVA indicated that the mean evaluation score and standard deviation of the sliding velocity of the bar were significantly affected by the interface condition $(\mathrm{p}<0.001)$. Post hoc analysis indicated that, under both dry and wet conditions, participants found the bar movement easier to control when either of the powders were applied than when no powder was applied ( $\mathrm{p} 0.001)$; however, the evaluation scores were not significantly different between the two powders $(\mathrm{p}>0.05)$. Post hoc t-testing revealed that both powders significantly stabilized the sliding velocity 
under wet conditions $(\mathrm{p}<0.05)$. Under dry conditions, powder application tended to reduce the standard deviation of the sliding velocity; however, the effect of powder was insignificant ( $p>0.05)$. Mean arrival time under each condition was less than $5.0 \mathrm{~s}(4.22-4.56 \mathrm{~s})$, with no significant differences across the interface conditions $(\mathrm{p}=0.48)$. The mean total sliding distance also was not significantly affected by the conditions $(p=0.35)$. These results indicate that the powders not only increased the controllability of sliding motion, but also stabilized the sliding movement of the grasped bar.

The relationship between the standard deviation of the sliding velocity of the bar and the controllability of bar sliding motion (quantified by the evaluation scores) is plotted in Fig. 5. A strong negative correlation is observed in this figure $\left(\mathrm{R}^{2}=0.92\right)$. This result suggests that reducing the variation in the sliding velocity of the grasped bar is crucial for increasing the controllability of the bar. The result also shows that the bar sliding velocity was less variable in the presence than in the absence of powders (for both powders), thereby indicating that powder improves the controllability of sliding the grasped bar.

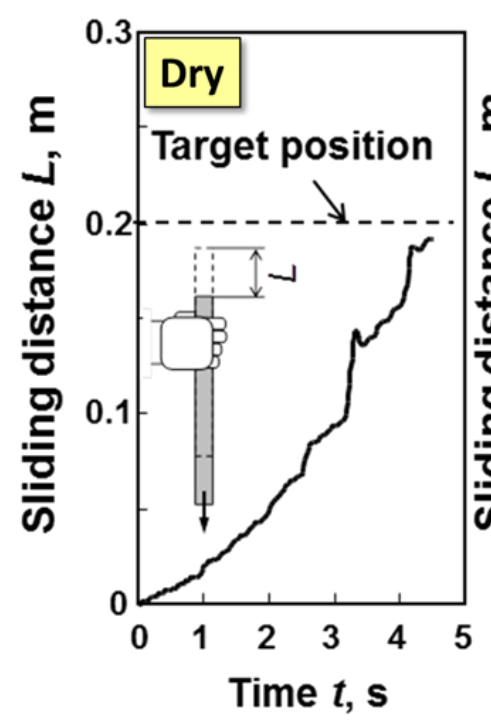

(a)



(b)

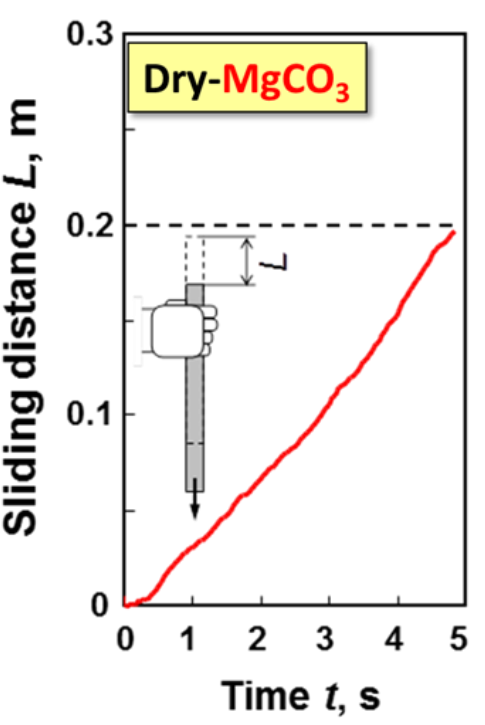

(c)

Fig. 3 Representative plot of temporal variation in sliding distance for (a) dry, (b) wet, and (c) dry- $\mathrm{MgCO}_{3}$ powder.

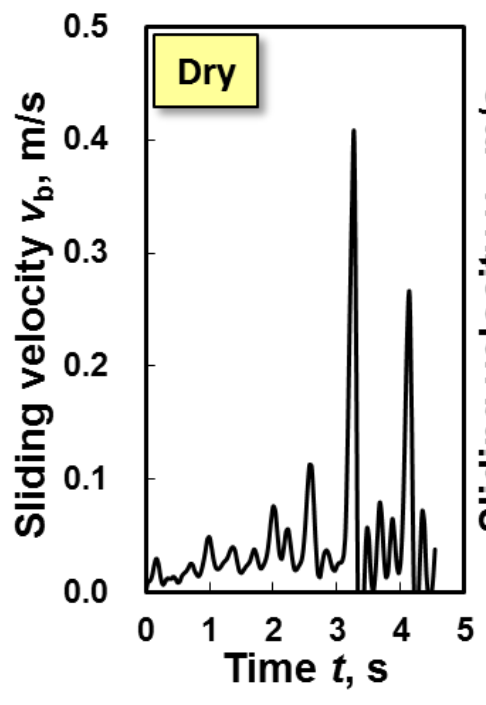

(a)

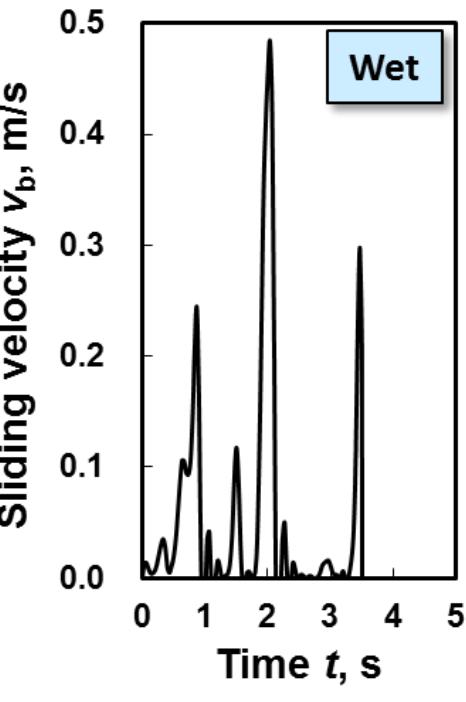

(b)

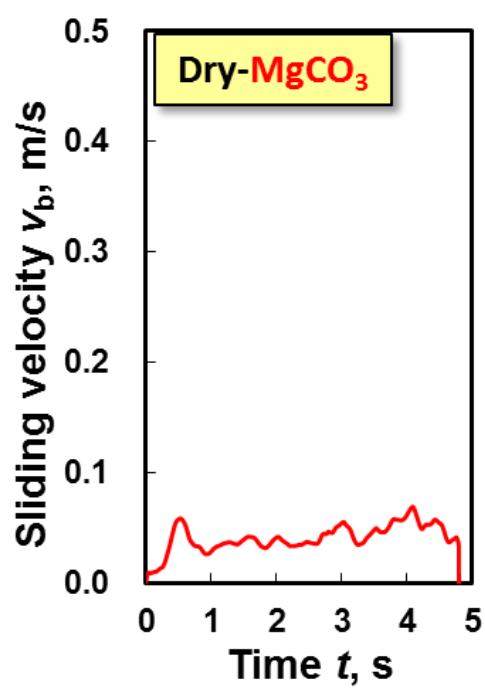

(c)

Fig.4 Representative plot of temporal variation in sliding velocity for (a) dry, (b) wet, and (c) dry- $\mathrm{MgCO}_{3}$ powder. 
Table 1 Mean (SD) values of variables in the sliding control test

\begin{tabular}{|c|c|c|c|c|c|c|c|}
\hline & $\begin{array}{l}\text { Dry w/o } \\
\text { powder }\end{array}$ & Dry- $\mathrm{MgCO}_{3}$ & Dry-Rosin & $\begin{array}{l}\text { Wet w/o } \\
\text { powder }\end{array}$ & Wet-MgCO ${ }_{3}$ & Wet-Rosin & $\begin{array}{l}p \text { values for } \\
\text { ANOVA }\end{array}$ \\
\hline Evaluation score $E$ & $\begin{array}{r}2.47 * * * \\
(0.64)\end{array}$ & $\begin{array}{c}4.20 * * * * * \\
(0.68)\end{array}$ & $\begin{array}{c}3.93 * * * * * * \\
\quad(0.80)\end{array}$ & $\begin{array}{r}1.33 * * \\
(0.49)\end{array}$ & $\begin{array}{c}4.07 * * * * * \\
(0.46)\end{array}$ & $\begin{array}{c}3.67 * * * * * * \\
\quad(0.98)\end{array}$ & $<0.001 *$ \\
\hline Time of arrival $T_{\mathrm{a}}, \mathrm{s}$ & $\begin{array}{l}4.45 \\
(0.66)\end{array}$ & $\begin{array}{c}4.56 \\
(0.58)\end{array}$ & $\begin{array}{c}4.22 \\
(0.35)\end{array}$ & $\begin{array}{c}4.41 \\
(0.87)\end{array}$ & $\begin{array}{c}4.35 \\
(0.34)\end{array}$ & $\begin{array}{c}4.24 \\
(0.64)\end{array}$ & 0.48 \\
\hline $\begin{array}{l}\text { Total sliding distance } \\
L_{\mathrm{t}}, \mathrm{m}\end{array}$ & $\begin{array}{l}0.201 \\
(0.012)\end{array}$ & $\begin{array}{c}0.195 \\
(0.004) \\
\end{array}$ & $\begin{array}{l}0.194 \\
(0.008)\end{array}$ & $\begin{array}{l}0.201 \\
(0.017)\end{array}$ & $\begin{array}{l}0.196 \\
(0.008)\end{array}$ & $\begin{array}{c}0.195 \\
(0.010)\end{array}$ & 0.35 \\
\hline $\begin{array}{l}\text { Standard deviation of } \\
\text { sliding velocity } \sigma_{\mathrm{v}} \text {, } \\
\mathrm{m} / \mathrm{s}\end{array}$ & $\begin{array}{c}0.052 \\
(0.027)\end{array}$ & $\begin{array}{c}0.030 * * * \\
(0.009)\end{array}$ & $\begin{array}{c}0.040 * * * \\
(0.016)\end{array}$ & $\begin{array}{l}0.094 \\
(0.046)\end{array}$ & $\begin{array}{c}0.032 * * * \\
(0.011)\end{array}$ & $\begin{array}{c}0.040 * * * \\
(0.015)\end{array}$ & $<0.001 *$ \\
\hline
\end{tabular}

*Significant difference among testing conditions, **Significant difference to Dry w/o powder, ***Significant difference to Wet w/o powder

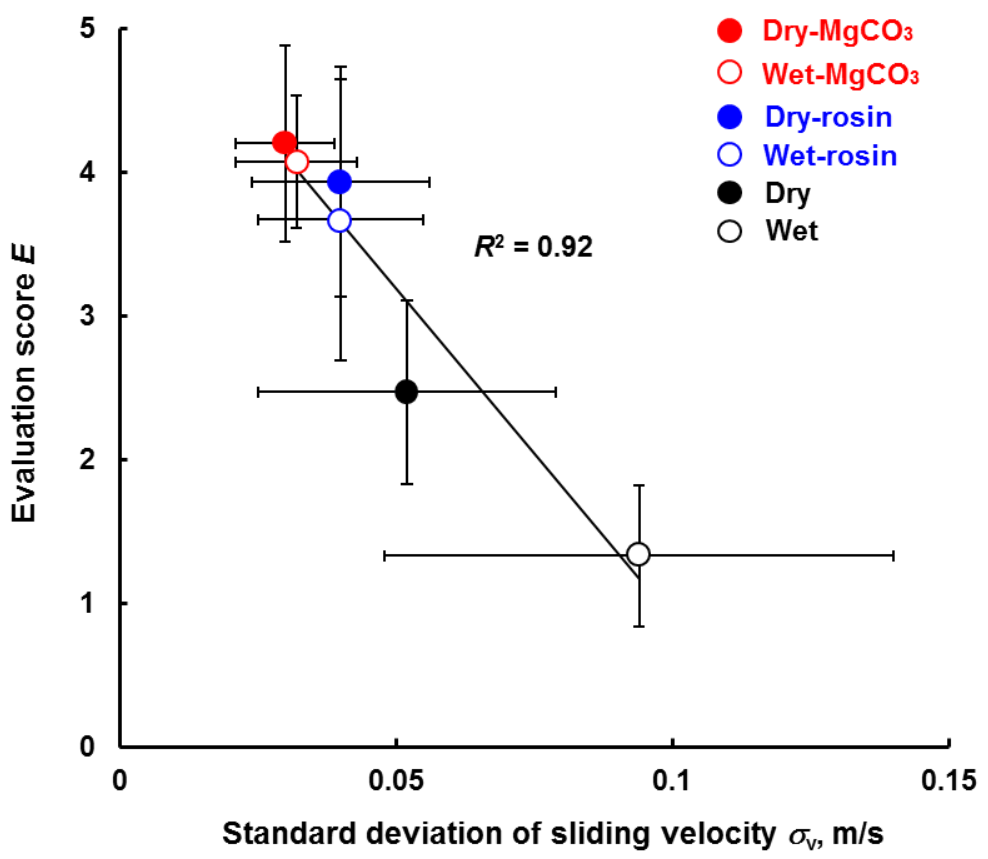

Fig. 5 Correlation between standard deviation of sliding velocity and evaluation score (the evaluation score quantifies the ease with which participants could control the vertical sliding motion of a cylindrical bar)

\subsection{Effect of powders on friction force between gloved hand and grasped bar during sliding}

Figure 6 shows representative temporal variations in the estimated friction force between gloved hand and the sliding cylindrical object. Results are shown for dry and wet conditions without $\mathrm{MgCO}_{3}$ powder and dry condition with $\mathrm{MgCO}_{3}$ powder. In the unpowdered cases, the friction force significantly fluctuates and irregular spikes are observed in Fig. 6(a) and (b). In contrast, as shown in Fig. 6(c), the friction force is significantly stabilized by the $\mathrm{MgCO}_{3}$ powder application. 
Figure 7 shows the mean value of standard deviation of friction force for each gloved-hand/bar interface condition. The error bar indicates the standard deviation. One-way repeated-measures ANOVA indicated that the mean standard deviation of friction force was significantly affected by the interface conditions ( $p<0.001)$. Post hoc analysis revealed that, under wet conditions, powder application significantly decreased the standard deviation of friction force $(\mathrm{p}<$ 0.005); however, under dry conditions, the effect of powder was insignificant ( $p>0.05$ ). There were no significant differences in the standard deviation of friction force between two powders under both dry and wet conditions.

A strong positive correlation was observed between the standard deviation of the friction force and the standard deviation of the sliding velocity of the bar $\left(\mathrm{R}^{2}=0.99\right)$. This means that the variation in friction force resulted in instability of the bar sliding motion. Thus, $\mathrm{MgCO}_{3}$ and rosin powder application decreased the friction force variation and stabilized the bar sliding motion, resulting in better controllability of the grasped bar.

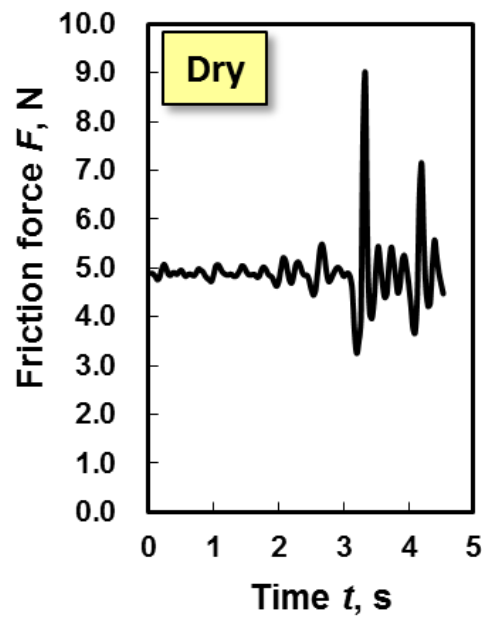

(a)

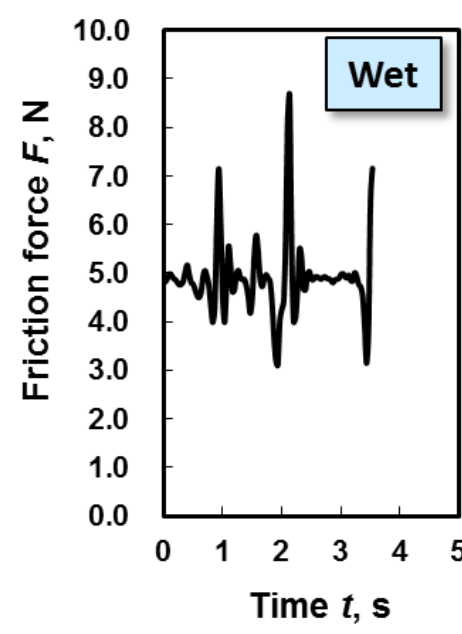

(b)

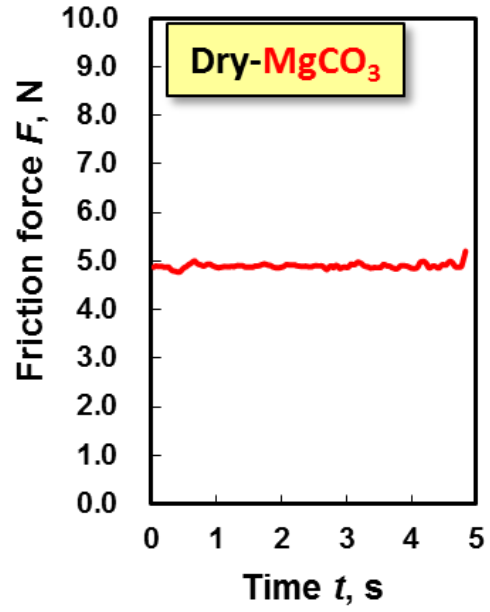

(c)

Fig. 6 Representative plot of temporal variation in friction force for (a) dry, (b) wet, and (c) dry- $\mathrm{MgCO}_{3}$ powder

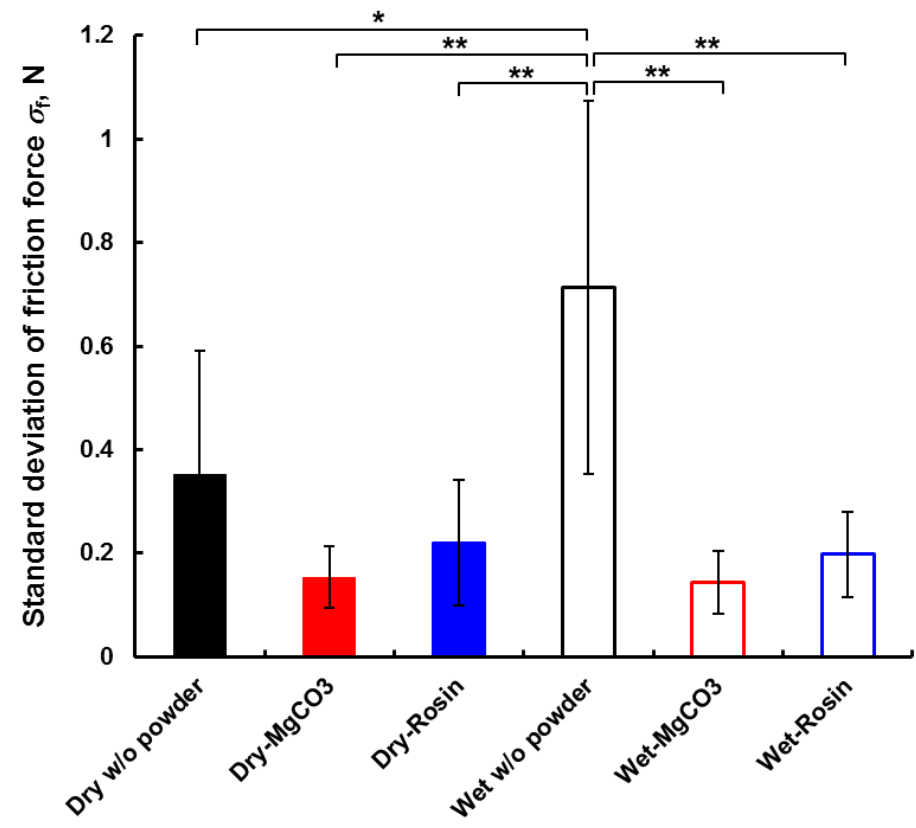

Fig. 7 Mean value of standard deviation of friction force during sliding control test. * and ** denote significant differences with $p<0.05$ and $p<0.005$, respectively. 


\subsection{Effect of powders on coefficient of friction}

Figure 8 shows the coefficient of friction as a function of sliding velocity under each lubrication condition. Under dry conditions, powder application (Fig. 8(b) and (c)) significantly reduced the coefficient of friction compared with unpowdered condition (Fig. 8(a)) under all sliding velocity and normal load conditions, possibly through reducing the contact area between rubber and steel ball, thus preventing adhesion of contacting surfaces. The effect of powder type was not significant under dry powdered condition as shown in Fig. 8(b) and (c). Under wet unpowedered condition (Fig. 8(d)), the coefficient of friction tended to decrease with increasing sliding velocity from $0.0001 \mathrm{~m} / \mathrm{s}$ to $0.01 \mathrm{~m} / \mathrm{s}$ and showed lower value than that under dry unpowdered condition (Fig. 8(a)); however, addition of $\mathrm{MgCO}_{3}$ (Fig. 8(e)) or rosin powder (Fig. 8(f)) negated this trend, yielding a slightly increased or constant coefficient of friction with increasing sliding velocity, similar to observations under dry, powdered conditions.

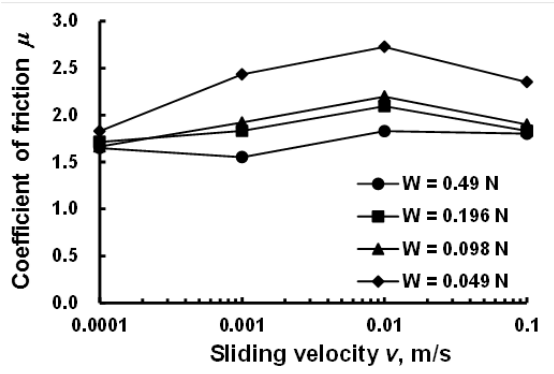

(a)

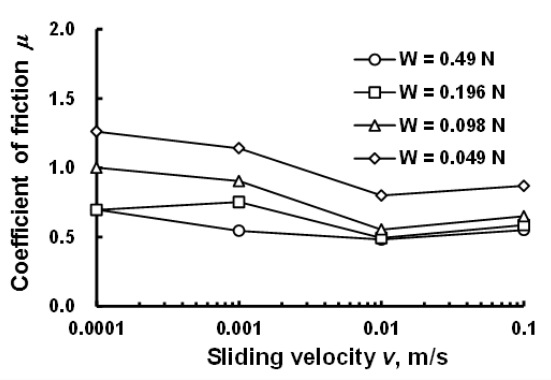

(d)

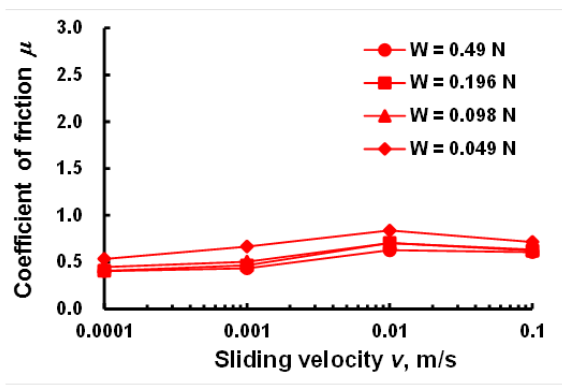

(b)

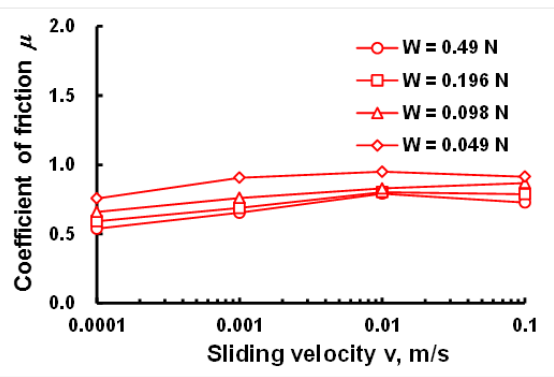

(e)

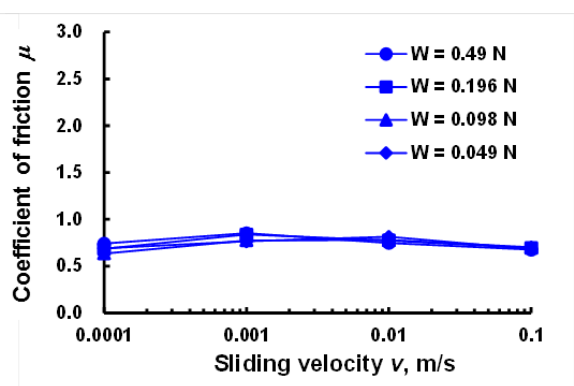

(c)

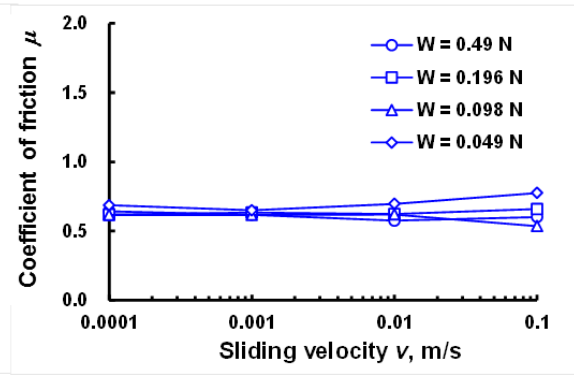

(f)

Fig. 8 Coefficient of friction as a function of sliding velocity; (a) dry, (b) dry- $\mathrm{MgCO}_{3}$, (c) dry-rosin, (d) wet, (e) wet- $\mathrm{MgCO}_{3}$, and (f) wet-rosin

\section{Discussion}

The simple bar sliding test suggests that $\mathrm{MgCO}_{3}$ and rosin powder stabilize the friction force between rubber-gloved hand and sliding object, which resulted in the increased stability of sliding motion of the grasped bar. The coefficient of friction between the rubber glove and stainless steel bar during sliding control test cannot be measured because of the lack of grip force measurement. Thus, the ball-on-plate sliding friction test was conducted in order to estimate qualitative impact of powder application on the coefficient of friction between rubber glove and stainless steel bar. The ball-on-plate sliding friction tests indicated that powder application reduced coefficient of friction between rubber and steel under dry condition as well as dissipating the negative dependence of coefficient of friction on sliding velocity under wet condition. The sliding contact condition in the ball-on-plate friction test was not identical to that at the interface between rubber-gloved hand and sliding bar and the different materials (natural rubber and urethane) were used in sliding control test and ball-on-friction test; however, the effect of powder application on the coefficient of friction observed in the ball-on-plate friction test could help in understanding possible mechanisms of stabilized sliding motion of the grasped bar. 
Prior to trial, the tangential force applied between hand and bar (corresponding to the bar weight) was less than the static friction force when participants grasped the bar without slipping. Participants then reduced their grip force to reduce the safety margin, i.e. the difference between tangential force and static friction force, and the bar started to slide downward through the hand once the tangential force reached the static friction force. Following slip onset, to retain constant sliding velocity, the grip force should be adapted to equalize the friction force $(F)$ and the bar weight $(\mathrm{mg}$ ). Furthermore, less adaptation of the grip force would be desired for easier control of the sliding motion.

Under dry unpowdered condition, the coefficient of friction between rubber-gloved hand and grasped steel bar could be significantly higher than that under other conditions as observed in the ball-on-friction test results (Fig. 8). With this high coefficient of friction, grip force variation could result in a large friction force variation and more grip force adaptation is needed. Therefore, participants found it difficult to control the sliding bar's motion with a constant speed under dry unpowdered conditions. On the contrary, low coefficient of friction requires a large grip force to retain the required friction force for a constant sliding velocity. $\mathrm{MgCO}_{3}$ and rosin powder application could reduce the coefficient of friction between rubber-gloved hand and grasped bar compared with dry unpowdered condition; however, their coefficient of friction was possibly high enough to yield a required friction force within the range of each participant's grip force.

Under wet conditions, we presume that a partial water film existing between sliding surfaces of rubber glove and steel bar reduced the coefficient of friction with increasing sliding velocity in the mixed lubrication regime (Adams, et al., 2007). This trend was observed in the ball-on-plate friction test results (Fig. 8 (d)). This negative coefficient of friction-sliding velocity characteristic causes the increased difficulty of adaptation of grip force and controlling the bar sliding motion: grip force must be varied with the sliding velocity. Because of their hygroscopic nature, the powders dried the contact interface ( $\mathrm{Li}$ et al., 2001) of the rubber glove and the bar. Thus, the coefficient of friction could be stabilized with respect to sliding velocity change as observed in the ball-on-plate friction test results under wet powdered conditions (Fig. 8 (e), (f)). Therefore, powder application stabilized friction force and the bar sliding motion under wet conditions at the same level as dry powdered conditions.

There was no statistically significant difference in the results for $\mathrm{MgCO}_{3}$ and rosin powdered conditions; however, the evaluation score and stability of sliding motion for the rosin powdered condition tended to be inferior to the $\mathrm{MgCO}_{3}$ powdered condition under both dry and wet conditions (see Table 1). Since rosin powder includes rosin in addition to $\mathrm{MgCO}_{3}$ powder, rosin powder could be sticky and show higher friction than $\mathrm{MgCO}_{3}$ powder; this is effective for preventing slip, but possibly decreases the stability of the sliding motion of the bar.

In this study, a rubber glove was used in the sliding control test to give a uniform test surface, which could limit the results of this study because the complex interaction between powder, skin and sweat needs to be understood to characterize the powders' real behavior. Another limitation of this study was to simulate the friction behavior of natural rubber glove and steel bar with ball-on-plate friction test using urethane rubber and steel ball siding contact. Only a single weight condition ( $500 \mathrm{gf}$ ) in the sliding control test also limits the results of this study because the bar weight could affect the level of safety margin due to a change in tangential force. In future work, the grip force between the gloved hand and the bar must be measured during the sliding test to calculate the coefficient of friction between them and clarify the details of the mechanism of improving controllability of sliding a vertically grasped bar.

\section{Conclusions}

The current study investigated the effect of $\mathrm{MgCO}_{3}$ and rosin powders, conventionally used as powdery anti-slip agents, on the controllability of sliding a vertically grasped cylindrical bar. A sliding control test indicated that both powders reduced the variation in sliding velocity of the grasped bar and improved the controllability of its sliding motion compared with unpowdered dry and wet conditions. Powder application decreased variation in the friction force between the rubber-gloved hand and grasped bar during sliding under dry and wet conditions. These results suggest that $\mathrm{MgCO}_{3}$ and rosin powders stabilize friction, thereby improving the sliding control of the grasped bar.

\section{Acknowledgment}

The authors would like to thank Toshihiro Shimakura and Takahiro Kawasaki for their help in performing the experiments. 


\section{References}

Adams, M. J., Briscoe, B. J., Johnson, S. A., Friction and lubrication of human skin, Tribology Letters, Vol. 26 (2007), pp. 239-253.

Amca, A. M., Vigouroux, L., Aritan, S., Berton, E., The effect of chalk on the finger-hold friction coefficient in rock climbing, Sports Biomechanics, Vol. 114 (2012), pp. 73-79.

André, T., Lefèvre, P., Thonnard, J. L., A continuous measure of fingertip friction during precision grip, Journal of Neuroscience Methods, Vol. 179 (2009), pp. 224-229.

Bahadur, S., Ludema, K. C., The viscoelastic nature of the sliding friction of polyethylene, polypropylene and copolymers, Wear, Vol. 18, (1971), pp. 109-128.

Blakemore, S. J., Goodbody, S. J., Wolpert, D. M., Predicting the consequences of our own actions: the role of sensorimotor context estimation, The Journal of Neuroscience, Vol. 18, (1998), pp. 7511-7518.

Bourne, R., Halaki, M., Vanwanseele, B., Clarke, J., Measuring lifting forces in rock climbing: effect of hold size and fingertip structure, Journal of Applied Biomechanics, Vol. 27, (2011), pp. 40-46.

Burstedt, M. K., Flanagan, J. R., Johansson, R. S., Control of grasp stability in humans under different frictional conditions during multidigit manipulation, Journal of Neurophysiology, Vol. 82, (1999), pp. 2393-2405.

Cole, K. J., Rotella, D. L. Harper J. G., Mechanisms for age-related changes of fingertip forces during precision gripping and lifting in ddults, The Journal of Neuroscience, Vol. 19, (1999), pp. 3238-3247.

Damian, D. D., Hernandez, A., Martinez, H., Pfeifer, R., Slip Speed feedback for grip force control, IEEE Transactions on Biomedical Engineering, Vol. 59, (2012), pp. 2200-2210.

de Freitas, P. B., Uygur, M., Jaric, S., Grip Force adaptation in manipulation activities performed under different coating and grasping conditions, Neuroscience Letters, Vol. 457, (2009), pp. 16-20.

Derler, S., Gerhardtm, L. C., Lenz, A., Bertaux, E., Hadad, M., Friction of human skin against smooth and rough glass as a function of the contact pressure, Tribology International, Vol. 42, (2009), pp. 1565-1574.

Flanagan, J. R., Wing, A. M., The stability of precision grip forces during cyclic arm movements with a hand-held load, Experimental Brain Research, Vol. 105, (1995), pp. 455-464.

Johansson, R. S., Westling, G., Roles of glabrous skin receptors and sensorimotor memory in automatic control of precision grip When Lifting Rougher or More Slippery Objects, Experimental Brain Research, Vol. 56, (1984), pp. 550-564.

Kim, M. S., Kim, I. Y., Park, Y. K., Lee, Y. Z., The friction measurement between finger skin and material surfaces, Wear, Vol. 301, (2013), pp. 338-342.

Li, F. X., Margetts S., Fowler, I., Use of 'chalk' in rock climbing: sine qua non or myth?, Journal of Sports Sciences, Vol. 19, (2001), pp. 427-432.

Ludema, K. C., Tabor, D., The friction and visco-elasitc properties of polymeric solids, Wear, Vol. 9, (1966), pp. 329-348.

Peter Wriggers P., Nackenhorst U, ed., IUTAM Symposium on Computational Contact Mechanics: The influence of contact pressure on the dynamic friction coefficient in cylindrical rubber-metal contact geometries (2007), pp. 257-275, Springer. 